\title{
A SISTEMÁtica dA VIOLAÇÃo DE DIREITOS HUMANOS POR EMPRESAS TRANSNACIONAIS: O EPISÓDIO DOS CARTÕES DE NATAL
}

\author{
THE SYSTEM OF VIOLATION OF HUMAN RIGHTS BY TRANSNATIONAL COMPANIES: \\ THE EPISODE OF CHRISTMAS CARDS
}

\author{
Elenise Felzke Schonardie ${ }^{1}$ \\ Mateus de Oliveira Fornasier ${ }^{2}$ \\ Carina Deolinda da Silva Lopes ${ }^{3}$
}

\section{RESUMO}

O artigo aborda o tema dos direitos humanos e a sua violação a partir da análise do caso de pedido de socorro de prisioneiros de uma prisão de Xangai (China), através da confecção de cartões de natal, em dezembro de 2019. O problema do trabalho centra-se na averiguação da efetividade dos princípios referendados pela ONU. A hipótese do texto está na dimensão da universalidade dos direitos humanos. $\mathrm{O}$ objetivo geral é analisar a partir dos três pilares dos princípios orientadores sobre empresas transnacionais e Direitos Humanos, referendado pela ONU, no caso dos cartões de natal. Inicialmente, trata da questão dos direitos humanos e a possibilidade de sua universalização. Na sequência, apresenta os princípios orientadores e recomendados pela ONU a serem observados pelas empresas transnacionais e sua atuação global e, por fim, analisa o caso do pedido de socorro feito por encarcerados de Xangai. O artigo tem como método de abordagem o hipotético-dedutivo, com técnica de pesquisa bibliográfica e análise de caso. Conclui-se que a operação global das empresas transnacionais se dá, muitas das vezes, à margem do direito local, necessitando do aporte principiológico das normas editadas pela ONU, como os princípios de proteger, respeitar e remediar direcionados a essas empresas. E, a globalização, em seu anverso, torna possível o conhecimento das violações de direitos humanos e possibilidade de sua cessação em razão das denúncias levadas ao conhecimento público.

Palavras-chave: Direitos humanos; Empresas transnacionais; Globalização, ONU.

\footnotetext{
${ }^{1}$ Doutora em Ciências Sociais pela Universidade do Vale do Rio dos Sinos - UNISINOS; Mestre em Direito pela Universidade de Santa Cruz do Sul - UNISC; Grduada em Direito pela UNIJUI; Professora do Programa de PósGraduação Stricto Sensu em Direito - Curso de Doutorado e Mestrado em Direitos Humanos da Universidade Regional do Noroeste do Estado do Rio Grande do Sul - UNIJUÍ, vinculada a linha de pesquisa "Democracia, Direitos Humanos e Desenvolvimento"; Professora do Curso de Graduação em Direito da UNIJUÍ; Advogada. Afiliação:Universidade do Nordeste do Estado do Rio Grande do Sul, Rio Grande do Sul - UNIJUI/Brasil ORCID:https://orcid.org/0000-0002-9240-5886 E-mail: elenise.schonardie@unijui.edu.br

2 Doutor em Direito pela Universidade do Vale do Rio dos Sinos (Unisinos), com pós-doutorado em Direito e Teoria (Law and Theory) pela University of Westminster (Reino Unido); Professor do programa de pós-graduação stricto sensu (mestrado e doutorado) em Direito da Universidade Regional do Noroeste do Estado do Rio Grande do Sul (Unijui).Afiliação:Universidade do Nordeste do Estado do Rio Grande do Sul, Rio Grande do Sul UNIJUI/Brasil. Lattes: http://lattes.cnpq.br/3316861562386174 ORCID: https://orcid.org/0000-0002-1617-4270. E-mail: mateus.fornasier@unijui.edu.br.

${ }^{3}$ Mestre em Direito; Doutoranda do Programa de Pós-graduação em Direitos Humanos da UNIJUI, Bolsista Capes, vinculada à linha de pesquisa do PPGDH/UNIJUí "Democracia, Direitos Humanos e Desenvolvimento"; orientanda da Profa. Dra. Elenise Felzke Schonardie; Advogada.Afiliação:Universidade do Nordeste do Estado do Rio Grande do Sul, Rio Grande do Sul - UNIJUI/Brasil. Lattes: http://lattes.cnpq.br/1912433621401452. ORCID:https://orcid.org/0000-0001-6109-8775. E-mail: lopesdeo@ hotmail.com
} 


\begin{abstract}
The article addresses the issue of human rights and their violation through the analysis of the case of a request for help from prisoners in a Shanghai (China) prison, through the making of Christmas cards in December 2019. The work focuses on ascertaining the effectiveness of the principles endorsed by the UN. The hypothesis of the text lies in the dimension of the universality of human rights. The general objective is to analyze from the three pillars of the guiding principles on transnational corporations and human rights, referenced by the UN, in the case of Christmas cards. Initially, it deals with the issue of human rights and the possibility of their universalization. Then, it presents the guiding principles recommended by the UN to be observed by transnational companies and their global action and, finally, it analyzes the case of the request for help made by prisoners in Shanghai. The article is based on a hypothetical-deductive approach, with a bibliographic research technique and case analysis. The conclusion is that the global operation of transnational companies often takes place outside local law, requiring the principled contribution of the norms edited by the UN, such as the principles of protect, respect, and remedy directed at these companies. And, globalization, in its inverse, makes it possible to become aware of human rights violations and the possibility of their cessation due to denunciations brought to public knowledge.
\end{abstract}

Keywords: Globalization, Human rights; Transnational companies; UN.

\title{
INTRODUÇÃO:
}

O artigo apresenta a questão dos direitos humanos e a violação desses pelas empresas transnacionais, frente aos princípios orientadores endossados pela ONU, analisando um caso especifico que demonstra a importância da busca pela concretização desses direitos e a importância de uma perspectiva universalista para os mesmos. E, apesar dos elevados níveis de desenvolvimento e tecnológia, a desconsideração da dignidade humana, ainda perdura, em muitos locais do mundo em pleno alvorecer do século 21 .

Em um mundo globalizado como o nosso, a ideia de reconhecimento, expansão e concretização dos direitos humanos tem sido tema recorrente das sociedades, por intermédio de casos ou ações com repercussão social mundial. Assim, com a amplitude da globalização muitos conflitos acabam emergindo, também, em âmbito transnacional. Conflitos esses que, em sua maioria, envolvem pessoas jurídicas de direito privado e o desrespeito aos direitos humanos em razão da competição global dos mercados de consumo.

Neste articulado, o problema de investigação centra-se na averiguação da efetividade dos princípios referendados pela ONU nas questões referentes a atuação de empresas transnacionais e a proteção de direitos humanos. Com isso, objetivamos de forma geral, a análise dos princípios orientadores sobre empresas e direitos humanos a sua efetividade frente ao episódio de vinte e dois de dezembro de dois mil e dezenove, envolvendo pedido de socorro através de texto de encarcerados 
de uma prisão de Xangai, na China, e envolvendo pedido de alerta para as organizações internacionais de proteção de direitos humanos.

A hipótese com a qual trabalhamos insurge da cognição da possibilidade da dimensão de universalidade dos direitos humanos mesmo, frente a atuação transnacional de pessoas jurídicas de direito privado que, buscam lugares para sua ação em que tais preceitos não sejam observados. $\mathrm{O}$ estudo observa os métodos de procedimento qualitativo e abordagem hipotética-dedutiva, a técnica de pesquisa bibliográfica, para a apresentação do caso dos cartões de natal com pedidos de socorro, que ganharam repercussão global a partir de sua descoberta, na Inglaterra, em dezembro de 2019. A temática é atual e propõe a reflexão sobre as diferentes formas de ação de empresas transnacionais, a contínua violação de direitos relacionados à dignidade humana e as possibilidades de concretização ou não dos mesmos.

\section{UMA CONVERSA INICIAL SOBRE DIREITOS HUMANOS: abrindo espaços sociais para o tema}

As questões que envolvem os direitos humanos, nesta década do ano de 2020, tem sido objeto de acaloradas discussões e uma multiplicidade de opiniões e divergências. Podemos até verificar, em algumas situações, certa repulsa e fragilização da temática dos direitos humanos em relação aquelas sociedades simpáticas a posturas autoritárias e conservadoras. Apesar disso, o tema dos direitos humanos resiste e é, extremamente necessário, frente as inúmeras fragilidades da condição humana em um mundo globalizado em que os paradigmas político e social, cederam lugar ao econômico.

Em princípio, cabem algumas considerações pontuais sobre os direitos humanos. Entendemos que os direitos humanos ${ }^{4}$ são para todas as pessoas da espécie humana e, devem ser observados e concretizados para a humanidade, como elevada condição civilizatória. Assim, a Declaração Universal de Direitos Humanos - DUDH, de 1948 estabeleceu um conjunto de direitos a serem observados pelos Estados-Nações que fazem parte da Organização das Nações Unidas ONU. Nesse sentido, nós enquanto membros da família humana precisamos de respeito À vida

\footnotetext{
${ }^{4}$ A dogmática jurídica dos direitos humanos apresenta duas correntes em relação ao mesmos; uma, universalista (a qual nos referimos) e, outra relativista (na qual o reconhecimento desses direitos dependeria de apoio e ratificação interna do Estado-Nação). "Atualmente, o conceito de direitos humanos é reconhecido como universal, como se poderá verificar na Declaração adotada pela Conferência Mundial de Viena sobre Direitos Humanos, em 1993, e nas Resoluções da ONU aprovadas por ocasião do 50ªniversário da DUDH, em 1998. Alguns céticos que questionam a universalidade dos direitos humanos devem ser recordados de que Estados tão geograficamente diversos como a China, o Líbano ou o Chile se encontravam entre aqueles que participaram na elaboração desse conceito, na segunda metade dos anos 40.”(MOREIRA; GOMES, 2014. p. 53-54)(grifo do autor).
} 
humana, trabalho digno, um meio ambiente equilibrado, alimentação de boa qualidade, moradia digna e demais condições que todo ser humano precisa para sobreviver.

O conceito de direitos humanos é salutar no sentido de entendermos que são direitos inerentes a todos os seres humanos, independentemente de nacionalidade, etnia, idioma, gênero, religião ou qualquer outra condição. Segundo Ban Ki-Moon, Secretário Geral das Nações Unidas em 2010, "Os direitos humanos são a fundação da liberdade, paz, desenvolvimento e justiça e cerne do trabalho das Nações Unidas em todo o mundo" (apud, MOREIRA; GOMES, 2014. p. 54).

O Direito Internacional dos Direitos Humanos estabelece as obrigações dos governos de agirem de determinadas maneiras ou de se absterem de certos atos, a fim de promover e proteger os direitos humanos e as liberdades de grupos ou indivíduos. E, desde o estabelecimento das Nações Unidas, em 1945, em meio a forte lembrança sobre os horrores da Segunda Guerra Mundial, um de seus objetivos fundamentais tem sido promover e encorajar o respeito aos direitos humanos para todos, conforme estipulado na Carta das Nações Unidas:

Considerando que os povos das Nações Unidas reafirmaram, na Carta da ONU, sua fé nos direitos humanos fundamentais, na dignidade e no valor do ser humano e na igualdade de direitos entre homens e mulheres, e que decidiram promover o progresso social e melhores condições de vida em uma liberdade mais ampla, ... a Assembleia Geral proclama a presente Declaração Universal dos Diretos Humanos como o ideal comum a ser atingido por todos os povos e todas as nações. (Preâmbulo da Declaração Universal dos Direitos Humanos, 1948).

Por meio do conceito de direitos humanos reconhecemos que todo ser humano pode desfrutar do conjunto de direitos que são inerentes à sua condição de membro da família humana (MOREIRA; GOMES, 2014), sem distinção de qualquer natureza, como já afirmado. Todavia, a Declaração Universal de Direitos Humanos, desde sua promulgação, tem dado origem a uma série de Convenções - Convenção Internacional de Direitos Humanos da $\mathrm{ONU}^{5}$ - que orientam os Estados em suas ações para promoção, garantia e efetivação das liberdades fundamentais e da dignidade humana. Mas, esses documentos internacionais não têm força de lei, pois caracterizamse, juridicamente, como soft law, ou seja, a observação dos seus preceitos no âmbito territorial de cada Estado vai depender da vontade e conveniência de cada país. Contudo, os Estados de tradição democrática, que constituem-se em estado democrático de direitos, a adoção e observação dos documentos internacionais de proteção e promoção dos direitos humanos, no âmbito territorial interno, compõe o conjunto de elementos que indicam seu nível civilizacional.

\footnotetext{
${ }^{5}$ Por exemplo: Convenção Internacional sobre a Proteção dos Direitos de Todos os Trabalhadores Migrantes e dos Membros de Suas Famílias (de 1990, com 45 Estados Partes), Convenção sobre os Direitos da Criança (de 1989, com 193 Estados Partes), Convenção sobre a Eliminação de Todas as Formas de Discriminação Racial (de 1965, com 173 Estados Partes), Convenção sobre a Eliminação de Todas as Formas de Discriminação contra as Mulheres (de 1979, com 186 Estados Partes), Pacto Internacional sobre os Direitos Civis e Políticos (de 1966, com 165 Estados Partes), entre outros.
} 
Nesse sentido, a busca por uma ética emancipatória, capaz de gerar a transformação social na vida das pessoas, a fim de efetivar os direitos humanos em sua plenitude é fundamental para concretizar as potencialidades humanas em prol dos desejos de igualdade e liberdade, sem violência e discriminação. Uma vez que,

É a ética que vê no outro um ser merecedor de igual consideração e profundo respeito, dotado do direito de desenvolver as potencialidades humanas de forma livre, autônoma e plena. Como um construído histórico, os direitos humanos não traduzem uma história linear, não compõem uma marcha triunfal, nem tampouco uma causa perdida. Mas refletem, a todo o tempo, a história de um combate mediante processos que abrem e consolidam espaços de luta pela dignidade humana. (PIOVESAN, 2009, p. 197).

Amartya Sem (2010, p.292) menciona em forma de crítica onde os direitos humanos não assumiriam exatamente uma forma legal e institucional, mas a forma de domínio da ética social, a autonomia moral dos direitos humanos depende da natureza de práticas éticas aceitáveis. Porém, questionamos, aqui, até que ponto essa ética é universal? Isto porque, na promoção da vida social, em um mundo cada vez mais interligado pelo fenômeno da globalização, os direitos humanos que entendemos como universais são continua e sistematicamente violados.

A observância aos preceitos de direitos humanos está imbricada na questão da alteridade, de reconhecer o outro como sujeito de liberdades e igualdade. A expansão e evolução da trajetória histórica dos direitos humanos ${ }^{6}$ tem demonstrado a nossa dificuldade em relação ao reconhecimento do outro como sujeito de direitos e garantias, ainda mais, quando esse outro apresenta-se como diferente (com outra cor, outra língua, outra cultura).

A Declaração Internacional de Direitos Humanos e os demais documentos internacionais de proteção desses direitos determina que Estados Partes observem os preceitos desses documentos e recomenda, aos referidos países, que não se envolvam em atividades específicas que afrontem os direitos do humanos, uma vez que, esses direitos são inerentes a cada pessoa, simplesmente, por ela ser um membro da espécie humana. Dessa forma, os direitos humanos formam uma completude de garantias que são fundadas no respeito à dignidade e valor da pessoa humana, daí sua característica de universalidade, pois em tese, devem ser observados sem qualquer forma de discriminação a todas as pessoas.

Outra característica dos direitos humanos é a sua inalienabilidade. Isso significa que, tratase de direitos intransferíveis e inegociáveis, não são passíveis de comercialização. Podemos dizer, em outras palavras que bens ou direitos inalienáveis são, segundo a tradição civilística, res extra

\footnotetext{
${ }^{6}$ Sobre a expansão e evolução da trajetória histórica dos direitos humanos, ver: Bedin, G., \& Schonardie, E. (2019). Os DIREITOS HUMANOS E O ACESSO À JUSTIÇA: UMA ANÁLISE HISTÓRICO-CONCEITUAL DE UM DIREITO FUNDAMENTAL PARA A CONVIVÊNCIA HUMANA PACÍFICA. Revista Direito Em Debate, 27(50), 75-86. https://doi.org/10.21527/2176-6622.2018.50.75-86.
} 
commercium. Ninguém pode ser privado dessas garantias. Porém, em situações específicas, esses direitos podem sofrer limitação, como por exemplo, o direito à liberdade que pode ser restringido se uma pessoa for considerada culpada de um crime, por juiz ou tribunal competente, observado o devido processo legal, como expresso no artigo 29 da DUDH.

Também, são direitos indivisíveis, inter-relacionados, interdependentes e imprescritíveis, uma vez que, é insuficiente respeitar apenas alguns direitos humanos e outros não. E, a violação dos direitos humanos não prescreve com o transcorrer do tempo. Na prática, a violação de um direito humano desencadeia o respeito por muitos outros direitos em razão da conexão e interdependência existente entre os mesmos. Portanto, não é possível reivindicar a observância aos direitos humanos de liberdade em detrimento aos direitos humanos de igualdade ou vice-versa, pois ambos são essenciais à dignidade humana.

No ano de 2018, a DUDH completou setenta anos desde sua promulgação. E, é oportuno lembrar que essa Declaração nasceu do desejo profundo de pessoas (personalidades internacionais e representantes de diversas nações) de impedir novas barbáries violadoras do conjunto de elementos que formam e fazem parte da condição humana que cada um nós traz consigo. A DUDH deve ser compreendida como padrão universal de direitos humanos que, em conjunto como Programa de Ação da Conferência Mundial de Viena de 1993, reconhecem a existência de diferentes "abordagens quanto à implementação dos direitos humanos com base em fatores históricos, religiosos e culturais, mas ao mesmo tempo, reiteraram a obrigação de todos os Estados de implementar todos os direitos humanos" (MOREIRA; GOMES, 2014, p. 56).

$\mathrm{O}$ espectro de abrangência dos direitos humanos é enorme, intenso e de alta complexidade nesse mundo globalizado. Entretanto, nos propomos a abordar na sequência alguns dos princípios referendados pela ONU às empresas transnacionais, que dizem respeito a proteção e promoção dos direitos humanos nas atividades desenvolvidas nos diferentes territórios, em nível global, nos quais atuam.

\section{PRINCÍPIOS RECOMENDADOS PELA ONU E A COMPLEXIDADE DO MUNDO REAL: GLOBALIZAÇÃO, EMPRESAS TRANSNACIONAIS E DIREITOS HUMANOS}

A globalização trouxe inúmeros pontos positivos e negativos às sociedades, seja no âmbito local, seja no âmbito global. Temos que a globalização é um fenômeno que afeta o globo como um todo favorecendo a percepção de diferentes referenciais culturais, sociais e a imposição de um projeto econômico neoliberal em face das comunidades locais, desafiando as garantias de direitos fundamentais e dentre tantas consequências o cumprimento e respeito aos direitos humanos universais. 
Boaventura de Sousa Santos (1997) entende a globalização como um processo pelo qual determinada condição ou entidade local estende a sua influência a todo o globo e, ao fazê-lo, desenvolve a capacidade de designar como local outra condição social ou entidade rival. A globalização é um fenômeno que vem abrangendo todos os meios sociais e profissionais, nada mais é exclusivo de um determinado espaço. Podemos evidenciar nesse contexto a abrangência de grandes marcas e grandes empresas, que trabalham e desenvolvem seus produtos em uma escala fenomenal, abrangendo todos os continentes do globo.

A agenda econômica da globalização vêm pressionando e flexibilizando a regulação interna dos Estados, pois, apesar de o território continuar existindo sob a regência de normas públicas da alçada nacional, as forças mais ativas do seu dinamismo atual têm origem externa (WLOCH; VIZZOTTO, 2016, p.98). A globalização que emergiu, nas últimas duas décadas do século 20, como consequência da intensificação dramática da transnacionalização da produção de bens e serviços e dos mercados financeiros, tem demonstrado a predominância da agenda econômica de grandes conglomerados transnacionais. Nesse sentido, é um processo através do qual as empresas multinacionais ascenderam a uma preeminência sem precedentes como sujeitos internacionais. (SANTOS, 1997).

No que tange a regulação interna dos Estados, podemos dizer que o direito passa por uma reconfiguração em decorrência dos processos globalizantes e das múltiplas possibilidades de escolhas advindas da complexificação social, favorecendo as diversas emissões de juridicidade, deslocadas da figura do ente estatal. Conforme Gregory Shaffer (2016,p. 250) o direito precisa ser pensado a partir de uma nova perspectiva, não sendo possível visualizar mais o jurídico a partir das lentes nacionais, apenas.

Assim, podemos pensar em um direito global que pode ser visto como multifacetado, hipercomplexo, contingente e policontextural, e se manifesta em redes especializadas, organizadas formal e funcionalmente, criadoras de uma identidade global estritamente setorial, as quais se reproduzem continuamente. (FORNASIER; FERREIRA, 2017, p. 75).

Neste tempo de globalização as chamadas empresas transnacionais alcançam uma posição determinante no sistema global, para além dos países em que iniciaram seus trabalhos. Isso, aliado a ideia de competitividade e busca pelo lucro e riqueza, não levando em consideração a mão de obra humana que perpassa, nesse processo, de produção e comercialização à apropriação desigual.

O termo transnacional suscita atenção, sendo que a própria Organização das Nações Unidas - ONU difundiu essa nomenclatura:

Uma empresa que independentemente do seu país de origem e de sua propriedade, podendo ser privada, pública ou mista, compre entidades locais em dois ou mais países, ligadas por controle acionário ou de outra forma que uma ou mais dessas entidades possam exercer influência significante sobre a atividade das demais e, 
em particular, para dividir conhecimento, recursos e responsabilidades umas com as outras. (UNCTAD, 2013).

Para além das empresas transnacionais, a globalização perpassa as mais diversas esferas, inclusive a jurídica efetuando comunicações com outras instituições estatais que, de certa forma, são afetadas pelos fenômenos globais, casos que se entrelaçam envolvendo e suscitando diversos conflitos, de diferentes ordens. No entanto, esses entes transnacionais conseguem transpor os limites internos dos estados, impondo a estes, uma agenda econômica que permita a satisfação de seus interesses e metas. ${ }^{7}$

Atualmente, observamos uma pluralidade de ordens jurídicas, como as dos estados nacionais e outros que não se reduzem exclusivamente aquelas como o regime da organização mundial do comércio, o corpo normativo que disciplina os investimentos internacionais, a ordem jurídica aplicável aos esportes por exemplo, a lex esportiva, ou a lex mercatória, nas transações no âmbito da Organização Mundial do Comércio - OMC, dentre outros. Em relação a lex mercatória, esta é um exemplo de regulação transnacional utilizada para abarcar relações comerciais complexas, algo para além de um direito costumeiro e pela necessidade de introdução de um termo que seja capaz de se referir a uma certa realidade a que as concepções tradicionais da ordem jurídica interna, não são mais capazes de se reportar. (MENDES, 2010, p. 20).

O problema do conflito entre ordens jurídicas não é novo, pois quando ordens jurídicas estatais envolvidas no mesmo caso reclamam soluções distintas, cabe ao direito internacional (público e/ou privado) enfrentar esses aspectos. Desse modo, passam a existir múltiplas possibilidades de regulação de condutas de empresas transnacionais, "não mais sendo cabível observar no ordenamento estatal a única possibilidade de regê-las, eis que o nível de organização das empresas transnacionais supera os limites em que este é soberano" (FORNASIER; FERREIRA, 2015, p. 412).

Desse modo, nossa atenção voltam-se para outras dificuldades, uma vez que, a teoria do direito que se defronta, de um lado, com o surgimento de ordens jurídicas transnacionais que desafiam as teorias tradicionais do direito e, de outro, com a necessidade de pensar as relações dessas ordens transnacionais com as ordens estatais. Os direitos humanos estão, também, abrangidos pelas situações atuais que perpassam o direito transacional e seus reflexos, comportando também a violação de tais direitos frente as empresas de natureza global.

\footnotetext{
${ }^{7}$ Sobre a globalização e suas implicações nas sociedades em nível local e as empresas transnacionais ver BEDIN, Gilmar Antonio; SCHONARDIE, Elenise Felzke; LEVES, Aline Michele Pedron. Os direitos humanos e o cosmopolitismo no panorama das cidades globais: desafios e paradoxos da contemporaneidade. DIREITOS CULTURAIS (ONLINE), v. 13, p. 107-126, 2018.
} 
O tema a respeito da conflituosa relação entre as empresas transnacionais e a proteção dos direitos humanos passou a ter destaque na agenda política internacional a partir da década de 1990; decorrência do processo de globalização corporativa, no qual se evidenciaram custos humanos decorrentes desse fenômeno em sua matriz econômica. As empresas transnacionais podem ser conceituadas como aquelas que possuem sede em um país e operam em, pelo menos, um país estrangeiro, sendo compostas tais entidades por várias empresas em rede, como conglomerados, cujo campo de comunicação e produção de sentido ultrapassa os limites dos Estados. Sendo que, em relação a regulação dessas empresas, há certa dificuldade dos Estados, pois sua regulação está adstrita as normativas tradicionais jurisdicionais territoriais. O que expõe a fragilidade da ordem política estatal diante da mobilidade transnacional dessas empresas. E, ainda que, os Estados tenham aderido aos tratados internacionais e tenham uma legislação até que satisfatória, não se é aplicado, em razão do grande poder econômico das transnacionais tem sobre o território em que estão inseridas, e sobre âmbito internacional. (VIEIRA; RIBEIRO).

Nesse contexto, o regime internacional de proteção dos direitos humanos apresentou, e de certa forma ainda apresenta, deficiências quanto à sua aplicação às empresas transnacionais. Isto porque, foi concebido para lidar com violações praticadas por Estados-partes dos tratados internacionais e não por entidades e corporações transnacionais.

A primeira iniciativa para lidar com a mencionada deficiência da temática, foi a proposta de um tratado internacional, no âmbito da ONU, denominado Normas de Responsabilidades de Corporações Transnacionais e Outras Empresas em Relação aos Direitos Humanos, que ficaram conhecidas como as "Normas". Tal regramento acabou por particularizar a discussão entre a comunidade empresarial e organizações em defesa dos direitos humanos. As empresas eram contrárias à adoção de um tratado internacional, uma vez que, vislumbravam que as "Normas" culminariam na "privatização dos direitos humanos"; e, os chamados ativistas, por sua vez, eram favoráveis à adoção de um tratado vinculante, que pudesse responsabilizar diretamente empresas no âmbito internacional por violações aos direitos humanos. (RUGGIE, 2014, p. 19).

A partir da identificação de casos de violação de direitos humanos por empresas transnacionais, foram realizadas amplas pesquisas, quando do desenvolvimento dos princípios orientadores endossados pela ONU, cujos resultados permitiram o estabelecimento de padrões que possam ser aplicados aos casos de violações a direitos humanos por parte das empresas. Toda via, é preciso identificar quais direitos, internacionalmente reconhecidos, são impactados negativamente por essas empresas; e; quais pessoas ou grupos de pessoas que são afetados negativamente; também, onde, qual o local (ou locais) em que as violações de direitos humanos ocorrem e, por quais setores da economia estão direta ou indiretamente envolvidos nessas violações. 
Salientamos que as ameaças aos direitos humanos decorrentes de atividades de empresas transnacionais deixam muito claro que seria um erro localizar o potencial para a violência apenas em atores estatais. $\mathrm{O}$ desenvolvimento de ações e obrigações para que as ordens privadas respeitem os direitos humanos é reação a essas formas de violência ocorridas entre tais entidades. (FISCHERLESCANO, 2015, p. 107). E, considerando, a atual estrutura do direito internacional em matéria de direitos humanos, as dificuldades na sua aplicação em face de violações praticadas por conglomerados empresariais globais, os motivos para criação das normas e dos tratados internacionais, e voluntarismo, para enfrentamento da questão, apoiamo-nos em uma nova abordagem heterodoxa, baseada em princípios, para regulamentação internacional da questão conflituosa entre as empresas transnacionais e os direitos humanos.

Diante da atuação global das empresas transnacionais a ONU, através de seu conselheiro John Gerard Ruggie, implementou os chamados princípios orientadores por meio do Conselho de Direitos Humanos das Nações Unidas (CDH/ONU) que, endossou, por unanimidade, os chamados Princípios Orientadores em junho de $2011^{8}$.

Tais princípios constituem a única orientação oficial que o Conselho e sua antecessora, a Comissão de Direitos Humanos, emitiram para Estados e empresas transnacionais em relação aos desafios da proteção de direitos humanos. Tais princípios foram estruturados em três pilares proteger, respeitar e reparar.

1.O dever do Estado de proteger contra abusos cometidos contra os direitos humanos por terceiros, incluindo empresas, por meio de políticas, regulamentação e julgamento apropriados; 2 . A responsabilidade independente das empresas de respeitar os direitos humanos, o que significa realizar processos de auditoria para evitar a violação dos direitos de outros e abordar os impactos negativos com os quais as empresas estão envolvidas; 3 . A necessidade de maior acesso das vítimas à reparação efetiva, por meio de ações judiciais e extrajudiciais. (RUGGIE, 2014, p. 23).

Sendo assim, a base é entender que aos Estados cabe a proteção, as companhias devem respeitar as diretrizes e aos prejudicados cabe o direito de buscar reparo aos seus danos. Criou-se uma base comum para a formulação dos Princípios Orientadores, base essa fundada na realização de estudos de referência sobre os principais desafios que o tema suscita.

Para além do lucro visado pelas empresas transnacionais, essas devem levar em consideração a vida do ser humano, do seu colaborador. E, se isto não for observado por iniciativa própria da empresa transnacional, deve ser imposto a mesmo o seu respeito em razão de legislação

\footnotetext{
${ }^{8}$ A fim de melhor gerir os desafios relativos a negócios e direitos humanos, o Conselho de Direitos Humanos das Nações Unidas aprovou em 16/06/2011 um novo conjunto de princípios orientadores globais para empresas concebidos para assegurar que estas não violem os direitos humanos no curso de suas operações e forneçam reparação quando da ocorrência de infrações. Ver mais: ONU (2020).
} 
internacional e nacional dos países em que estão sediadas. Isso, tendo em vista que "uma empresa deve integrar valores dentro de cada atividade empresarial direcionando todo o empreendimento e procurando maneiras de impactar positivamente com suas atividades a sociedade na qual está inserida e faz parte" (GUEDES, 2000, p. 13).

É importante ressaltar as considerações sobre como tais princípios podem ser aperfeiçoados, em especial, em áreas que regulam a prática empresarial, mas que não levam em consideração a proteção dos direitos humanos.

\begin{abstract}
A História nos ensina que os mercados representam os maiores riscos - à sociedade e às empresas em si - quando seu âmbito e poder ultrapassam o alcance das bases institucionais que permitem seu bom funcionamento e garantem sua sustentabilidade política. Isso está acontecendo agora, e um de nossos principais desafios de governança é adaptar o regime de direitos humanos de forma que ele possa fornecer proteção mais efetiva a pessoas e comunidades contra violações dos direitos humanos relacionadas a empresas. (RUGGIE, 2014, p. 264).
\end{abstract}

Verificamos que as grandes empresas e as corporações multinacionais funcionam e estão em todo o mundo, enquanto as visões políticas fragmentadas e baseadas em estados nacionais ficam limitadas em territórios. A proposição é no sentido de haver uma visão policêntrica, abrangendo soluções interligadas não apenas entre Estados territoriais, mas também entre corporações, agentes de mercado, sociedade civil e do poder intrínseco da ideia de direitos humanos.

Assim os princípios orientadores que demandam sobre empresas e direitos humanos expressam essa questão de contemplação de abordagem policêntrica quando lida com as lacunas deixadas por uma governança e ainda representa uma plataforma normativa e de orientação política que direciona as políticas dos Estados, corporações, outras ordens e agentes sociais envolvidos. Nesse sentido:

Estes Princípios Orientadores devem ser entendidos como um todo coerente e devem ser interpretados, individual e conjuntamente, em termos de seu objetivo de aprimorar normas e práticas no que diz respeito a empresas e aos direitos humanos de forma a atingir resultados tangíveis para indivíduos e comunidades impactadas e, contribuindo, assim, para uma globalização socialmente sustentável. (BRASIL, 2019, p. 11).

Diante do que evidenciamos a respeito da globalização, do crescimento mundial de empresas transnacionais, importante também salientar que a atual governamental dos estados deixa lacunas em sua governança, o que favorece ambientes que permitem atos de abuso ou violação aos direitos humanos pelas empresas, mesmo quando não existe, inicialmente, a intenção e, sem que haja sanção punitiva ou ações de remediação. (RUGGIE, 2014, p. 137).

Do caminho percorrido pelas organizações internacionais o conjunto de tratados e abordagens de responsabilidade social voluntária devem remediar de forma suficiente as lacunas que serão deixadas nos próximos tempos. Sendo que, para que exista esperança de se ter êxito para 
com o futuro (próximo), é preciso reconhecer, interligar melhor e promover as múltiplas esferas de governança que moldam a conduta das corporações multinacionais. (RUGGIE, 2014, p. 137).

Do mesmo modo, o quadro referencial com a ideia de proteger, de respeitar e de remediar, junto com os princípios orientadores objetivaram estabelecer uma esfera normativa comum mundial. E, um aparato confiável a ser aplicado em âmbito transnacional, visando a não violação de direitos humanos no curso da operação de conglomerados empresariais transnacionais.

Na sequência, apresentamos o episódio dos prisioneiros de Xangai que clamavam por ajuda ao se denominarem escravos de uma empresa de confecção de cartões de natal.

\section{O CASO DOS CARTÕES DE NATAL: a violação de direitos humanos}

Como podemos observar até aqui inicialmente tratamos do fenômeno da globalização e de seus impactos junto ao território mundial em aspectos globais e locais. Também, abordamos a necessidade de concretização e respeito aos direitos humanos pelas empresas multinacionais em operação em diversos continentes e países, mesclando diversidades de localização, culturas e de mão de obra.

Da preocupação com tal concretização e, principalmente, pelos muitos momentos em que os direitos humanos foram violados em cenários como os que descrevemos, emerge a abordagem acerca dos princípios orientadores que buscam então proteger, respeitar e remediar a violação de direitos humanos. Um episódio que chamou nossa atenção, refere-se aos prisioneiros de Xangai, que prestavam trabalho para uma empresa com atuação transnacional, na confecção de cartões de Natal e, que escreveram num cartão um pedido de socorro, em dezembro 2019.

Em 22 de dezembro de 2019, Florence, com seis anos de idade, moradora de Tooting, no sul de Londres, mencionou em entrevista à BBC News que estava escrevendo seu "sétimo ou oitavo cartão" para amigos quando viu "que alguém já havia escrito em um deles". (ESTADÃO, 2019). A mensagem era bastante típica de um discurso de quem sofre as derradeiras formas de violações de direitos humanos, mencionando que quem escreve o cartão eram prisioneiros estrangeiros em Xangai, forçados a trabalhar contra a vontade, implorando, ainda, socorro a alguma organização de direitos humanos.

A empresa na qual os cartões foram comprados é a Tesco, uma empresa multinacional varejista, de origem britânica, que atua em redes de hipermercados. Após a divulgação do fato pela mídia televisiva e pela internet a Tesco suspendeu a produção de cartões de Natal, referindo em nota que "Nós nunca permitiríamos o trabalho forçado em nossa rede". A empresa disse, ainda, que retiraria da lista de fornecedores dos cartões a Zheijiang Yunguang Printing, caso fique constatado que eles usam trabalho de detentos. (G1, 2019). 
Ainda, segundo o noticiado, no cartão de natal divulgado, também, havia o nome de Peter Humphrey, um britânico que estava preso no mesmo presidio do autor da, em Xangai, desde 2015 sob a acusação de violar as leis chinesas sobre a vida privada quando morava no país. Em entrevista ao G1 o jornalista mencionou que sabe de onde partiu a mensagem e, que a vida na prisão de Xangai é sombria, ressaltando que bloco de celas de prisioneiros estrangeiros alojam cerca de duzentos e cinquenta pessoas, que vivem um "cotidiano muito sombrio", com 12 prisioneiros por cela. (G1, 2019). Ressaltou, ainda, que os prisioneiros dormem em beliches de ferro muito enferrujadas e com um colchão de cerca de $1 \mathrm{~cm}$ de espessura por baixo; lembrou, ainda, das condições climáticas adversas tanto no verão quanto no inverno e que os presos acordam por volta das cinco horas e trinta minutos da manhã, todos os dias, e têm que ir para a cama novamente por volta das vinte e uma horas e trinta minutos. Que os trabalhos eram, anteriormente, eram voluntários e que serviam, basicamente, para a aquisição de dinheiro para compra de sabão ou pasta de dente. Porém, atualmente, o trabalho se tornou obrigatório.

A violação de direitos humanos ocorrida neste episódio, não é a primeira, tampouco, será a última. Também, verificamos a ocorrência de casos de trabalho forçado e mão de obra escrava na China, com mais frequência do que gostaríamos, pois trata-se de um país em franca expansão internacional, que produz manufaturas das mais diversas ordens para o ocidente como um todo, mas que mantem um rígido regime de controle interno, não adotando as recomendações internacionais da ONU em seu território, muito embora, faça parte da comunidade internacional.

Outros casos de repercussão já ocorreram. Como em 2012, quando uma carta manuscrita veio de Sun Yi, relatando os abusos que enfrentou enquanto estava preso no Campo de Trabalho Masanjia, na cidade de Shenyang, província de Liaoning. Essa carta foi descoberta dentro de um kit de decoração de Halloween vendido por uma loja Kmart, no Oregon, Estados Unidos, no seu texto ficou descrito as condições difíceis no campo, dias de trabalho de quinze horas sem interrupção, incluindo nos fins de semana ou feriados, torturas e abuso verbal.

Buscamos apresentar apenas um caso que chamou atenção recentemente pelas possibilidades que em conjunto com outros casos já ocorridos, evidenciam que através da globalização e do fortalecimento e crescimentos das empresas transnacionais, as consequências humanas, como o desrespeito aos seus direitos, podem ocorrer nos mais diversos locais. Na maioria das vezes, essas violações ocorrem esses locais bem distantes dos mercados consumidores.

Todavia, como efeito rebote, essas violações assim que descobertas, são noticiadas em nível global, prejudicando a imagem das empresas transnacionais envolvidas e a possibilidade de boicote dos produtos pelos seus consumidores. Como os casos que embasaram o desenvolvimento dos pelares dos princípios orientadores entre as empresas e Direitos Humanos, descritos na Obra de 
John Gerad Ruggie (2014), como casos de repercussão envolvendo a Nike, a Shell, entre outras gigantes transnacionais.

Todavia, essas grandes corporações que se envolvem em escândalos de violação de direitos humanos, buscam convencer os seus consumidores de que nada sabiam, de foram enganadas. No caso da rede do hipermercado Tesco, a mesma afirmou que conta com um sistema de controle exaustivo, e que a fábrica, Zheijiang Yunguang Printing, segundo tem informações passou por um controle independente em novembro, não tendo sido observado nenhum elemento que sugerisse a violação de normas internacionais e nacionais de direitos humanos, que proíbem o trabalho em prisões, e que o fato teria levado a uma ruptura de contrato forma imediata e definitiva.

Observamos aqui a concretização de conceitos importantes, inicialmente o conflito transnacional envolvendo ordens jurídicas de diferentes Estados, com diferentes culturas e entendimentos, mas que abrangem direitos humanos comuns e garantias fundamentais que poderá ser averiguado e solucionado através da resolução pacífica e educativa do que com represálias e sanções.

O quadro referencial dos Princípios elaborados a partir de normas de direitos humanos preexistentes, representam um momento histórico na consolidação de parâmetros normativos aplicáveis à conduta das empresas em relação aos Direitos Humanos, sendo considerados só o "fim do início", como apontou Ruggie (2014). É imprescindível que as empresas transnacionais e os Estados onde estas operam tenham comprometimento para com a pauta de proteção de direitos humanos, atuando no mercado global de maneira não violatória.

Em casos como o apresentado observamos que poderão os princípios orientadores referendados pela ONU trazer a concretização uma nova dinâmica, de sistemas de governança, na qual agentes públicos e privados, corporativos e civis compensem suas deficiências e busquem uma atuação focada no fortalecimento das relações a serviço da plenitude dos direitos humanos.

\section{CONCLUSÃO}

O tema do presente trabalho envolveu a questão da perspectiva da violação a qualquer custo dos direitos humanos, a atuação das empresas transnacionais e a análise do caso de pedido de socorro por prisioneiros através de cartões de natal, em dezembro de 2019. O problema do trabalho deteve-se em averiguar se os pilares dos princípios orientadores para atuação de empresas transnacionais, referendados pela ONU desde 2011, tem sido efetivos. Nesse sentido, verificamos que embora tenhamos conhecimentos acerca da dimensão da universalidade dos direitos humanos, mesmo assim, há uma propensão à incidimos em uma compreensão calcada na concretização de 
interesses econômicos com fins lucrativos e particulares, como os das empresas transnacionais, frente ao respeito com os direitos humanos.

Nosso objetivo geral foi efetivado em analisar a partir dos três pilares ou quadro referencial dos princípios orientadores sobre empresas transnacionais e direitos humanos, referendado pela ONU e o caso dos cartões de natal. Apresentamos o quadro referencial abrangendo o dever do Estado de proteger os direitos humanos de violações praticadas por terceiros, inclusive empresas, a responsabilidade independente das empresas de respeitar, não violar, os direitos humanos e de verificar as necessidade das vítimas de violações de direitos humanos terem acesso a mecanismos efetivos de remediação, tanto em âmbito judicial ou extrajudicial.

Por fim, após a análise do contorno sobre os direitos humanos e os pilares referendados pela ONU sobre os princípios de proteger, respeitar e remediar entre empresas e direito humanos. Em relação ao episódio de denúncia de violação de direitos, através da confecção de cartões de natal, observamos que as empresas transnacionais tentam afastar sua responsabilidade com o episódio, aduzindo total desconhecimento e a imediata ruptura contratual com os envolvidos.

Apesar das desculpas e ações tomadas, somente, após a divulgação midiática do fato, em escala mundial, é que há, publicamente, a tomada de ação no sentido de evitar a ocorrência de novas operações violadoras de direitos, por parte dos grandes conglomerados empresariais. A sociedade civil tem um papel fundamental nesse contexto, o papel de cobrar, publicamente, dessas empresas transnacionais, o comprometimento para com os princípios e direitos referendados pela ONU e pelos estados em que atuam. E, mesmo diante dos interesses particulares dessas corporações globais, em relação ao lucro e a força que possuem, temos a possibilidade de reclamar das empresas transnacionais, em tempos de globalização, o seu comprometimento para com a dignidade humana e o conjunto de direitos e princípio, até então, desenvolvidos por nossas sociedades.

\section{REFERENCIAS BIBLIOGRÁFICAS:}

BEDIN, Gilmar A.; SCHONARDIE, Elenise F. Os direitos humanos e o acesso à justiça: uma análise histórico-conceitual de um direito fundamental para a convivência humana pacífica. Revista Direito Em Debate, 27(50), 2019, p.75-86. Disponível em: https://doi.org/10.21527/21766622.2018.50.75-86

BEDIN, Gilmar Antonio; SCHONARDIE, Elenise Felzke; LEVES, Aline Michele Pedron. OS direitos humanos e o cosmopolitismo no panorama das cidades globais: desafios e paradoxos da contemporaneidade. DIREITOS CULTURAIS (ONLINE), v. 13, p. 107-126, 2018.

BRASIL. Princípios orientadores sobre empresas e direitos humanos. Disponível em: https://www.mdh.gov.br/todas-as-noticias/2019/outubro/Cartilha_versoimpresso.pdf. Acesso em: 11. Jan. 2020. 
DE MATTOS ROCHA, Patrícia Barcelos Nunes. Direitos humanos, globalização e soberania. Disponível em: <http://www.boletimjuridico.com.br/m/texto.asp?id=1729>. Acesso em: 07 mar. 2019.

FORNASIER, Mateus de Oliveira; FERREIRA, Luciano Vaz. Regulação do risco nanotecnológico e normas do sistema ISSO: da possibilidade de uso criativo do direito global transnacional. Revista paradigma, Ribeirão Preto - SP, a. XXII, v. 26, n. 1, p. 75-102 Jan/Jun 2017.

FORNASIER, Mateus de Oliveira; FERREIRA, Luciano Vaz. A regulação das empresas transnacionais entre as ordens jurídicas estatais e não estatais. Revista de Direito Internacional, Brasília, v. 12, n. 1, 2015 p. 395-414.

FORNASIER, Mateus de Oliveira; SILVA, Thiago dos Santos. Arbitragem e Lex sportiva: o caso do Tribunal Arbitral do esporte (TAS). Revista Eletrônica de Direito Processual - REDP. Ano 11. Volume 18. Número 2. Maio/Ago. 2017. Rio de Janeiro.

G1. Menina encontra pedido de ajuda de trabalhador chinês em cartão de Natal. Disponível em: https://g1.globo.com/mundo/noticia/2019/12/22/menina-encontra-pedido-de-ajuda-detrabalhador-chines-em-cartao-de-natal.ghtml. Acesso em: 04. Jan. 2020.

GUEDES, Rita de Cássia. Responsabilidade social e cidadania empresariais: conceitos estratégicos para as empresas face à globalização. Montevideo, v. 401, p. 2002-2008, 2000. Disponível em: <http://www.lasociedadcivil.org/wpcontent/uploads/2014/11/cassia_guedes.pdf>. Acesso em: 13 jul. 2019.

FISCHER-LESCANO, Andreas. Uma "força justa e não violenta"? Uma crítica do direito na sociedade global. Tempo soc. [online]. 2015, vol.27, n.2, pp.103-127. ISSN 0103-2070. https://doi.org/10.1590/0103-2070201525. Acesso em: 14. Fev. 2020.

MENDES, Rodrigo Octávio Broglia. Arbitragem, Lex mercatória e Direito estatal: um análise dos conflitos ortogonais no Direito Transnacional. São Paulo: Quartier Latin, 2010.

MOREIRA, Vital; GOMES, Carla Marcelino. Compreender os direitos humanos: manual de educação para os direitos humanos. Coimbra: Coimbra Editora, 2014.

NEVES, Marcelo. Transconstitucionalismo. 1. ed. São Paulo: WNF Martins Fontes, 2009.

ONU. A conferência das Nações Unidas sobre o comércio e desenvolvimento. Disponível em: http://www.unctad.org/Templates/Page.asp?intItemID=1418\&lang=1. Acesso em: 22. Dez. 2019. ONU. Conselho de Direitos Humanos aprova princípios orientadores para empresas. Disponível em: https://nacoesunidas.org/conselho-de-direitos-humanos-aprova-principiosorientadores-para-empresas/ . Acesso em 30. Mai. 2020.

OLIVEIRA, Odete Maria de (Coord.). Relações Internacionais e Globalização: Grandes Desafios. Ed.Unijuí, Rio Grande do Sul, 1997.

O ESTADÃO. Mensagens de presos na China é encontrada em cartões de natal. Disponível em: $\quad$ https://internacional.estadao.com.br/noticias/geral,mensagem-de-preso-na-china-eencontrada-em-cartao-de-natal-vendido-em-supermercado-britanico,70003134488. Acesso: 24. Dez. 2019. 
PIOVESAN, Flávia.Temas de direitos humanos. São Paulo: Saraiva, 2009.

RUGGIE, John Gerad. Quando negócios não são apenas negócios. As corporações multinacionais e os direitos humanos. São Paulo: Planeta sustentável, 2014.

RUGGIE, John Gerad. Empresas e direitos humanos. Parâmetros da ONU para proteger, respeitar e reparar. Disponível em: https://www.socioambiental.org/sites/blog.socioambiental.org/files/nsa/arquivos/conectas_princip iosorientadoresruggie_mar20121.pdf. Acesso em: 10. Jan. 2020.

SHAFFER, Gregory. Theorizing Transnational Legal Ordering. Annual Review of Law and Social Science, 2016, v. 12, p.231- 253.

SANTOS, Boaventura de Sousa. Uma concepção multicultural de direitos humanos. Lua Nova: Revista de Cultura e Política, $\mathrm{n}^{\circ}$. 39. São Paulo. 1997. Disponível em: http://www.scielo.br/scielo.php?script=sci_arttext\&pid=S0102-64451997000100007. Acesso em: 19. Dez. 2019.

VIEIRA, Diego Fernandes. RIBEIRO, Daniela Menengoti Gonçalves. Responsabilidade social das empresas transnacionais: afronta à tratados internacionais de proteção dos direitos humanos por ineficácia normativa dos estados. XI EPCC Anais Eletrônico. 29 e 30 de outubro de 2019 http://rdu.unicesumar.edu.br/bitstream/handle/123456789/3560/DIEGO\%20FERNANDE S\%20VIEIRA.pdf?sequence=1\&isAllowed=y. Acesso em: 05. Fev. 2020.

WLOCH, Fabrício; VIZZOTTO, Juliana Nunes. Globalização e superação da soberania moderna. Revista da Faculdade de Direito da UFRGS, Porto Alegre, n. 34, p. 82-98, ago. 2016.

Trabalho recebido em 24 de junho de 2020

Aceito em 30 de agosto de 2021 